\title{
Arabidopsis Gene Family Profiler (aGFP) - user-oriented transcriptomic database with easy-to-use graphic interface Nikoleta Dupl'áková ${ }^{1,2}$, David Reňák ${ }^{1,2,3}$, Patrik Hovanec ${ }^{4}$, Barbora Honysová ${ }^{5}$, David Twell ${ }^{6}$ and David Honys*1,2
}

Address: ${ }^{1}$ Laboratory of Pollen Biology, Institute of Experimental Botany ASCR v.v.i., Rozvojová 263, 16500 Prague 6, Czech Republic, ${ }^{2}$ Department of Plant Physiology, Faculty of Science, Charles University in Prague, Viničná 5, 128 44, Prague 2, Czech Republic, ${ }^{3}$ Department of Plant Physiology and Anatomy, Faculty of Biological Sciences, University of South Bohemia, Branišovská 31, 37005 Keské BudEjovice, Czech Republic, ${ }^{4}$ Krymská 8/122, 10100 Praha 10, Czech Republic, ${ }^{5}$ Laboratory of Cell Biology, Institute of Experimental Botany ASCR v.v.i., Rozvojová 263, 16500 Prague 6, Czech Republic and ' ${ }^{6}$ epartment of Biology, University of Leicester, Leicester, LE1 7RH, UK

Email: Nikoleta Dupl'áková - duplakova@ueb.cas.cz; David Reňák - renak@ueb.cas.cz; Patrik Hovanec - patrikhov@gmail.com; Barbora Honysová - honysova@ueb.cas.cz; David Twell - twe@leicester.ac.uk; David Honys* - honys@ueb.cas.cz

* Corresponding author

Published: 23 July 2007

BMC Plant Biology 2007, 7:39 doi:10.1 I86/147|-2229-7-39
Received: 2 February 2007

Accepted: 23 July 2007

This article is available from: http://www.biomedcentral.com/I47I-2229/7/39

(C) 2007 Dupl'áková et al; licensee BioMed Central Ltd.

This is an Open Access article distributed under the terms of the Creative Commons Attribution License (http://creativecommons.org/licenses/by/2.0), which permits unrestricted use, distribution, and reproduction in any medium, provided the original work is properly cited.

\begin{abstract}
Background: Microarray technologies now belong to the standard functional genomics toolbox and have undergone massive development leading to increased genome coverage, accuracy and reliability. The number of experiments exploiting microarray technology has markedly increased in recent years. In parallel with the rapid accumulation of transcriptomic data, on-line analysis tools are being introduced to simplify their use. Global statistical data analysis methods contribute to the development of overall concepts about gene expression patterns and to query and compose working hypotheses. More recently, these applications are being supplemented with more specialized products offering visualization and specific data mining tools. We present a curated gene family-oriented gene expression database, Arabidopsis Gene Family Profiler (aGFP; http:// agfp.ueb.cas.cz), which gives the user access to a large collection of normalised Affymetrix ATHI microarray datasets. The database currently contains NASC Array and AtGenExpress transcriptomic datasets for various tissues at different developmental stages of wild type plants gathered from nearly 350 gene chips.
\end{abstract}

Results: The Arabidopsis GFP database has been designed as an easy-to-use tool for users needing an easily accessible resource for expression data of single genes, pre-defined gene families or custom gene sets, with the further possibility of keyword search. Arabidopsis Gene Family Profiler presents a user-friendly web interface using both graphic and text output. Data are stored at the MySQL server and individual queries are created in PHP script. The most distinguishable features of Arabidopsis Gene Family Profiler database are: I) the presentation of normalized datasets (Affymetrix MAS algorithm and calculation of model-based gene-expression values based on the Perfect Match-only model); 2) the choice between two different normalization algorithms (Affymetrix MAS4 or MAS5 algorithms); 3) an intuitive interface; 4) an interactive "virtual plant" visualizing the spatial and developmental expression profiles of both gene families and individual genes.

Conclusion: Arabidopsis GFP gives users the possibility to analyze current Arabidopsis developmental transcriptomic data starting with simple global queries that can be expanded and further refined to visualize comparative and highly selective gene expression profiles. 


\section{Background}

Completion and annotation of the Arabidopsis thaliana genome represented a major step in plant genetic research [1]. This knowledge enabled gene prediction, assignment of functional categories and gave an opportunity to study gene and chromosome organization including the distribution of transposable elements. Finally it has enabled the characterization of global gene expression patterns at the transcriptome level at different developmental stages and under various physiological and stress conditions. Efforts to reveal the biological functions of thousand of genes and their integration into proteome, metabolome and interactome networks has become the principal focus of many studies and represents key objective of the 2010 Project [2]

A number of efficient and accurate gene expression analysis technologies to determine the expression levels of individual genes have been widely exploited in recent decades (Northern blot analysis, quantitative reverse transcription-PCR, cDNA library screening). Most of these methods enable analysis of the expression of single or relatively few selected genes. For the discovery of partial or whole gene functional or regulatory networks, the development of high-throughput technologies is essential with genome-wide transcriptomic studies providing a major input [3]. Several such methods have been developed including, cDNA fingerprinting [4], serial analysis of gene expression - SAGE [5], massively parallel signature sequencing - MPSS [6], high-density DNA oligonucleotide probe microarrays [7,8] or cDNA arrays [9]. DNA microarray technologies are among the most frequently used methods for parallel global analysis of gene expression. These methods are based on the principle of selective and differential hybridization between sample target molecules and immobilized DNA probes. Hybridisation to probes arrayed on a solid surface report the relative abundance of DNA or RNA target molecules by fluorescent signal detection $[10,11]$. Microarray technologies now belong to the standard functional genomics toolbox $[12,13]$ and have undergone massive development leading to increased genome coverage, accuracy and reliability. Whole Genome microarrays developed by Affymetrix (Santa Clara, CA, USA) in collaboration with Syngenta represented the first standard in genome wide transcriptomic studies in plants. Whole genome Affymetrix ATH1 GeneChips cover about $76 \%$ of the Arabidopsis thaliana genes [14]. Moreover, the introduction of the Minimum Information About Microarray experiments (MIAME) as standard documentation for array experiments and in transcriptomic databases, increasing the value and comparability of microarray data [15].

The number of experiments exploiting microarray technology has markedly increased in recent years. Not sur- prisingly, there are potential difficulties in navigating between different available data sets. Microarray expression data are deposited on servers, many of which are publicly accessible. Public plant microarray data are deposited in several databases including ArrayExpress [16], GEO [17], NASCarrays [18] and the Stanford Microarray Database [19-21]. Currently these databases store several thousands of individual datasets and some of these offer on-line tools for data normalization, filtering, statistical testing and pattern discovery [22-26].

In parallel with the rapid accumulation of transcriptomic data, on-line analysis tools are being introduced to simplify their use. Global statistical data analysis methods contribute to the identification of overall gene expression patterns and to query and compose new working hypotheses based on these findings $[11,12,27,28]$. More recently, these applications are being supplemented with more specialized products offering visualization and specific data mining tools. Genevestigator, Botany Array Resource, Arabidopsis co-expression tool, and Expression Profiler offer Web-based tools to analyse large microarray datasets. Genevestigator offers two types of queries: a gene-centric approach and a genome-centric approach, which are represented by several analysis tools; Gene Correlator, Gene Atlas, Gene Chronologer, Response Viewer and the MetaAnalyzer, that is among the most sophisticated complex amongst available microarray analysis toolboxes [29,30]. Botany Array Resource offers similar services supplemented with tools for discovery and analyses of cis-elements in promoters [31]. Expression Profiler (EP) provides tools for hierarchical and K-groups clustering, clustering comparison, similarity search or the signature algorithm [32,33]. The more specialized PathoPlant database on plant-pathogen interactions and components of signal transduction pathways related to plant pathogenesis also harbors gene expression data from Arabidopsis thaliana microarray experiments to enable searching for specific genes regulated upon pathogen infection or elicitor treatment [34,35]. Finally, Arabidopsis Co-Expression Tool (ACT) allows users to identify genes with expression patterns correlated across selected experiments or the complete data set and offers the novel clique finder tool [36-38].

In this article we introduce Arabidopsis Gene Family Profiler (arabidopsisGFP, aGFP), a web-based gene expression database with visualization tools. During programming, we took into account that for many microarray data users, extraction of global expression patterns of single genes or gene families can be time-consuming and its visualization difficult. Moreover, the use of various normalization algorithms in individual experiments makes direct comparison of genes of interest within various datasets uncertain. To solve these issues, we devel- 
oped aGFP to provide the user with two normalization and gene detection algorithms and a "virtual plant" Arabidopsis Gene Family Profiler facility that enables users to obtain a global expression profile of user specified and/or pre-defined gene families. These attributes of aGFP contribute a useful resource for the rapid bioinformatic analysis of Arabidopsis gene expression data through comparative expression profile analysis in a gene familybased context.

\section{Construction and content}

The Arabidopsis Gene Family Profiler (aGFP) database was designed to give users the possibility to visualize expression patterns of individual genes, pre-defined gene families or user-defined gene sets in various tissues and at different developmental stages of wild type Arabidopsis thaliana plants. aGFP largely exploits microarray experiments obtained through the NASC AffyWatch transcriptomics service [39]. We adopted the general concept "from simple to complex". In the first approximation, an arithmetical mean expression signal from multiple experiments is displayed. In subsequent steps the user can choose to display expression data for individual plant organs or tissues at particular growth stages. This is accompanied by the option of progressive replacement of arithmetical means by individual expression values. So the user has the option to choose the different levels of visualization to suit needs. Finally, the user can switch from "virtual plant" visualization to a simple bar chart (standard or log-scaled) or tabulated display and can browse through individual experiments down to normalized or even raw data extracted from individual gene chips. Gene family data can also be visualized as a colorized spot chart.

Although the idea of web-based database tools is not novel, aGFP database offers a quick and interactive display of gene expression profiles using the virtual plant facility as well as alternate more conventional outputs. A novel feature of aGFP is that it enables the evaluation of the impact of normalization procedures on microarray expression data as well the possibility of rapid definition of user-defined families or gene groups. Simultaneously, aGFP serves as a facile and synoptic developmental reference guide for expression profiles of individual genes or gene families in wild-type Arabidopsis thaliana plants.

\section{Data resources}

The arabidopsisGFP database covers transcriptomic experiments accumulated from wild type Arabidopsis thaliana plants of various ecotypes grown under normal physiological conditions. Original raw microarray data were obtained from Nottingham Arabidopsis Stock Centre (NASC) through the AffyWatch service [39]. In order to ensure the quality and compatibility of expression data only microarray experiments using Affymetrix ATH1 whole genome arrays with at least two biological replicates were included. To date, arabidopsisGFP database covers transcriptomic data from 345 microarrays covering 120 experiments.

\section{Programming}

aGFP is composed as a relational MySQL database and Web server application, which is programmed in PHP script language [PHP:Hypertext Preprocessor]. Gene expression data are presented by dynamic HTML web pages with several types of graphic output. Graphs were generated using PHP module jpgraph [40]. HTML code was programmed to be correctly displayed in all commonly used internet browsers (Microsoft Internet Explorer/Mozilla Firefox/Opera). The user exploits a webbased interface for acquisition of custom-defined data. A user-friendly intuitive web-based interface is designed to enable simple and rapid navigation in aGFP. The aGFP database was created using general-to-specific strategy enabling the user to obtain a certain amount of information at every step with progressive targeted specification as the query develops.

\section{Data normalization}

All gametophytic and sporophytic datasets were normalized using freely available dChip 1.3 software [41]. The reliability and reproducibility of datasets was ensured by the use of duplicate or triplicate hybridization data in each experiment, normalization of all arrays to the median probe intensity and the use of normalized CEL intensities of all arrays for the calculation of model-based gene-expression values based on the Perfect Match-only model $[42,43]$. A given gene was scored as 'expressed' when it gave a reliable expression signal in all replicates. An expression signal value of ' 0 ' means that the detection call value was 'absent' or 'marginal' in at least one replicate provided. In arabidopsisGFP, the facility is provided to instantly switch between transcriptomic data normalized by two different algorithms - MAS 5.0 or MAS 4.0.

\section{Annotation pages}

Annotation of individual experiments is in accordance with MIAME standard [15]. Arabidopsis thaliana growth stages were according to Boyes et al. [44]. Affymetrix gene chips harbour several oligonucleotide probe types - prevalent unique probe sets (_at) accompanied by identical probe sets (_s set) and probes in a mixed probe set (_x set). Moreover, progressive Arabidopsis genome annotation has led to a reduction in the number of unique probe sets that has resulted in a reduction in the number of reliably 'present' genes. For these reasons, genes represented by these ambiguous probe sets were not included in the database [45]. This fact was taken into account and the aGFP database is regularly updated. Each locus in aGFP 
database is associated with relevant annotation released by TAIR (currently version 6) [46], and direct links to other web resources are available for each gene - TIGR $[47,48]$, MPSS [49], TAIR [50,51], MIPS [52,53].

\section{Definition of gene families and superfamilies}

arabidopsisGFP contains lists of pre-defined gene families and superfamilies enabling the rapid comparative visualization of expression profiles of their members. Genes in arabidopsisGFP are organized into two hierarchical levels consisting of gene families and superfamilies. All data were assembled from various relevant resources, the majority from TAIR - Arabidopsis Gene Family Information [54] and AGRIS [55,56]. Gene families were further organized in a different manner as gene family subclasses to different extent in each family and source. In order to simplify the different sub-divisions from different data sources, we rearranged them carefully and used only two levels, gene family and superfamily.

\section{Utility and discussion Data selection}

At the aGFP home page, the user can select the search category (AGI number, BAC locus, Gene name, keyword) and two other input parameters; the gene detection algorithm (MAS4.0 or MAS5.0) and the source of expression data (AtGenExpress or NASCArrays). To make aGFP as comfortable as possible to use, at any stage of the query the user has the possibility to directly switch options between these pairs of parameters. This represents a distinct feature of the aGFP database that enables direct comparison of the influence of the detection algorithm or data resource on expression profiles.

aGFP database presents data normalised using two different algorithms, empirical MAS 4.0 and statistical MAS 5.0. Although MAS4.0 is believed to yields more false-positive calls [57], our analyses of four developmental stages of pollen development showed that the MAS5.0 detection algorithm tended to eliminate a number of genes originally detected as expressed by MAS4.0 and which were experimentally verified to be so [58]. This was often the case even for highly expressed genes (B. Honysová and D. Honys, unpublished results), highlighting the added value of the empirical MAS4.0 detection algorithm and comparative analysis.

Experiments included in the aGFP database are presented in two different subsets. The first subset contains data obtained within a scope of the AtGenExpress project [59], the second comprises all other datasets deposited at NASC and was labeled NASCArrays [26]. The reason for this separation was that AtGenExpress contains a structured set of experiments, involving Columbia-0 plants grown under comparable conditions to provide a gene expression atlas at several developmental stages. On the contrary, NASCArrays contains experiments carried out in various ecotypes grown under various conditions. Data in each subset are presented using several different graphical displays and, the user has an option to instantly switch between subsets in each environment (Fig. 1).

The other key feature of aGFP is the possibility to select pre-defined gene families and superfamilies. In subsequent steps, expression data for family members can be extracted down to the level of individual genes. Moreover, the user has also the possibility to work with customdefined gene sets based on various search options (AGI number, Gene number, BAC locus, keyword search).

\section{Data visualization}

The aGFP database provides users with several different visualization formats. Apart from standard tables or bar charts (Fig. 2, 3, 4), an interactive virtual plant is used. The virtual plant comprises several growth stages defined according to Boyes et al. [44]. A white (low)-yellow-green (high) scale is used to depict the relative expression signals of individual genes, or gene families throughout the Arabidopsis life cycle. Mouse-over pointing to complex organs/tissues (i.e. flowers) causes opening of more detailed graphics showing individual organs (ie. sepals, petals, stamens, pistils and pollen; Fig. 5). This is in accordance with the adopted aGFP database concept "from simple to complex".

In addition to the virtual plant and bar chart graphics, expression profiles can also be visualized as interactive colorized spot charts or heat maps. The colorized spot chart uses a colour scale identical with that of the virtual

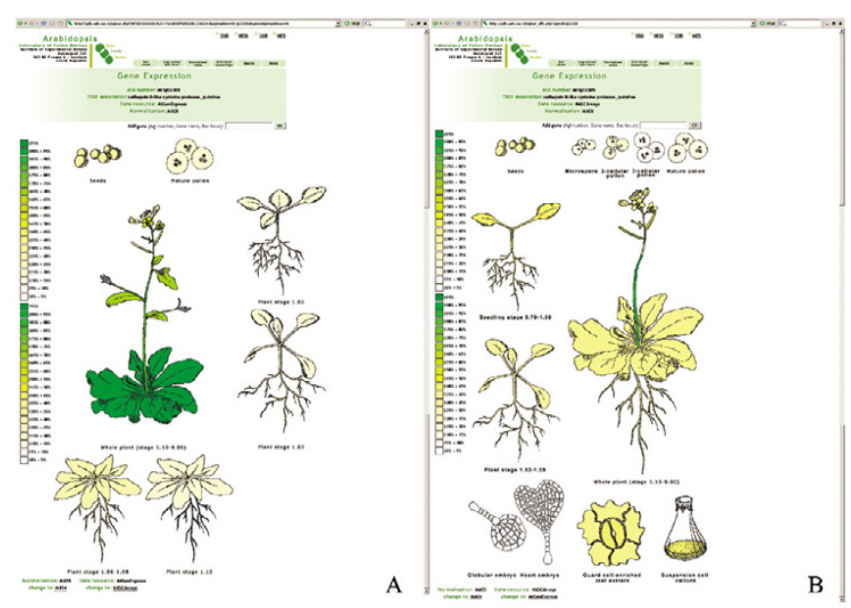

Figure I

Visualisation of gene search results using interactive "virtual plant". AtGenExpress (A) and NASCArrays (B) expression data for At lg02305 are shown. 


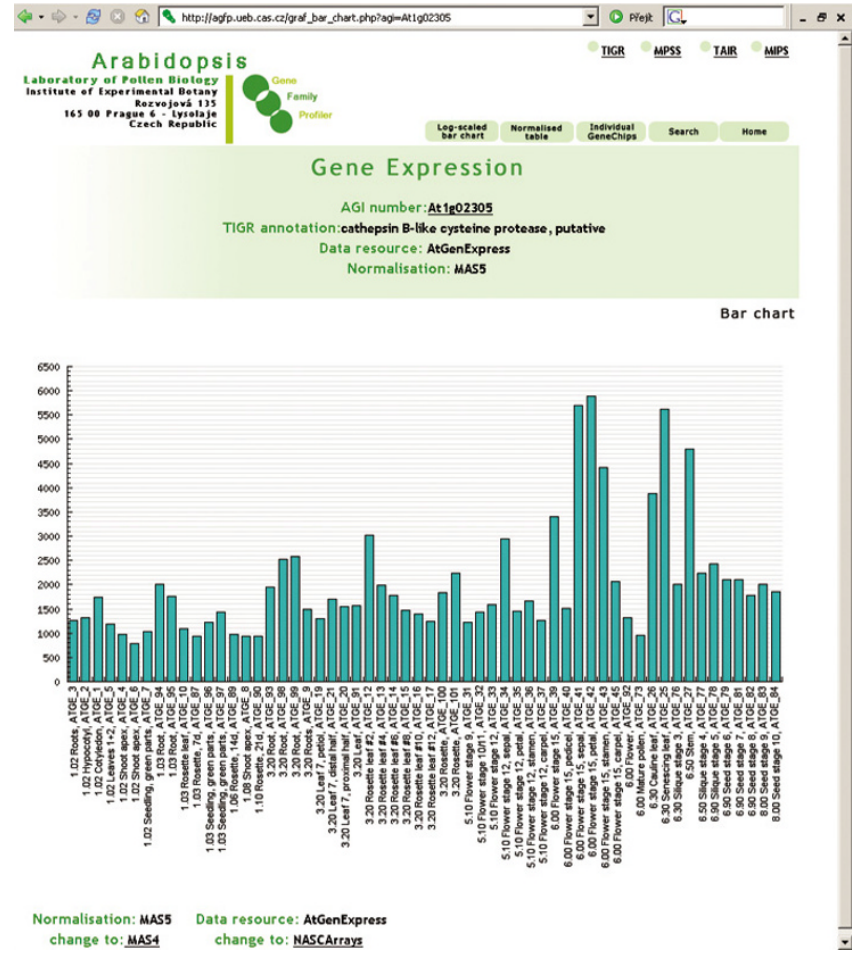

Figure 2

Expression data visualisation. Visualisation of At I g02305 gene expression using Bar chart option.

plant (Fig. 6). The interactivity of modeling is based on the possibility of ad hoc addition and removal of genes to and from a currently active set. Moreover, each spot contains information about expression signal value and experiment that is activated by mouse-over. Therefore visualized expression data are not merely summarized, but instead represent direct output from individual microarray experiments.

\section{Data accessibility and legend}

The complete datasets used in the aGFP database are described in the Legend available from the homepage and it is possible to trace the origin of all datasets. Moreover, data can be downloaded for individual and selected gene sets as a TAB-delimited text. This enables the direct import of downloaded data into spreadsheet editors such as Excel and database software such as Access and FileMaker. This text file contains a list of developmental and morphological stages, normalized expression data for the selected normalization algorithm and data source.

\section{Conclusion}

arabidopsisGFP is a microarray expression database of wild type Arabidopsis thaliana plants grown under physiological conditions. It gathers data from experiments using Affymetrix ATH1 whole genome arrays with two or more
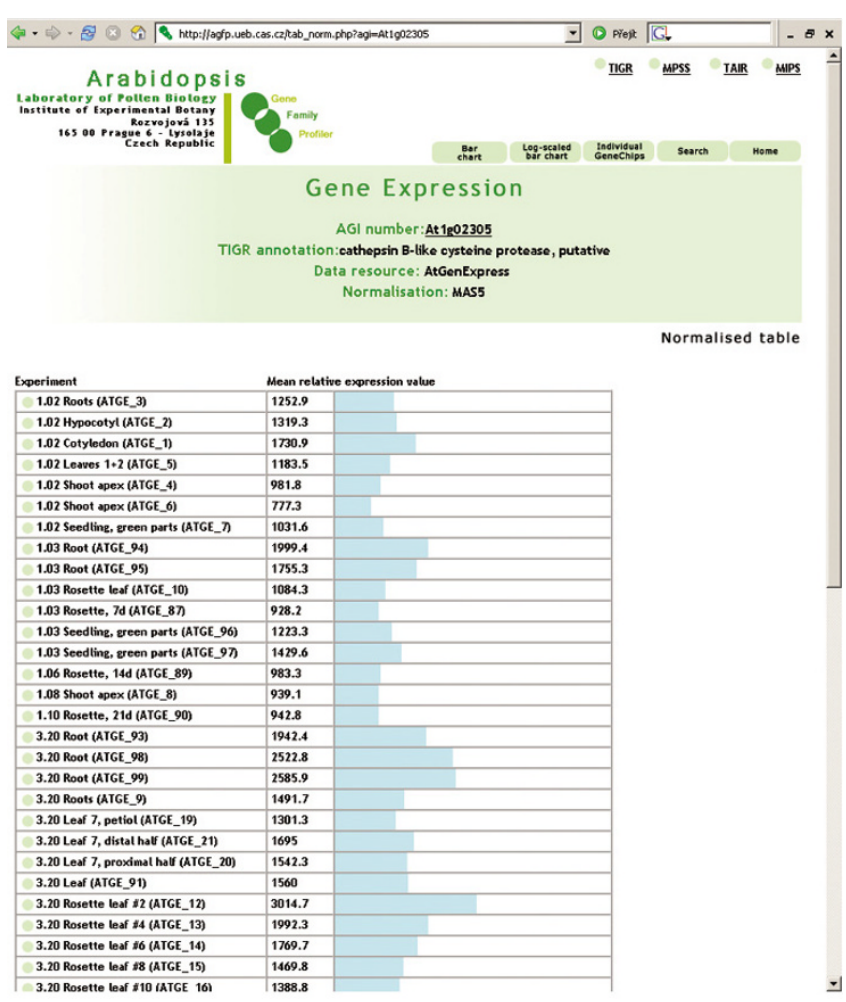

Figure 3

Expression data visualisation. Visualisation of At l g02305 gene expression using Normalised table option.

biological replicates. From the outset, it has been created as intuitive user-oriented web-tool employing a "generalto-specific" concept enabling the user to obtain certain amount of information at every step with progressive specification and refinement. The aGFP database contains several gene selection and grouping tools including predefined gene families. It also provides the user with different gene expression visualization options including a unique "virtual plant" graphic display. Easy switching of visualization options gives the user the possibility to rapidly select the most suitable form of data presentation. A novel advantage of the aGFP database is the provision of alternative normalization treatments of microarray data using statistical (MAS5.0) and empirical algorithms (MAS4.0). Together with the facile switch between these detection algorithms it provides the opportunity to instantly assess the reliability of gene expression data. Arabidopsis Gene Family Profiler represents a versatile tool for facile visualization of transcriptomic data that can be exploited in genome-led queries of gene and gene family functions and regulation.

\section{Availability and requirements}

The aGFP database is freely accessible and its concept offers the possibility to extract and visualize expression 


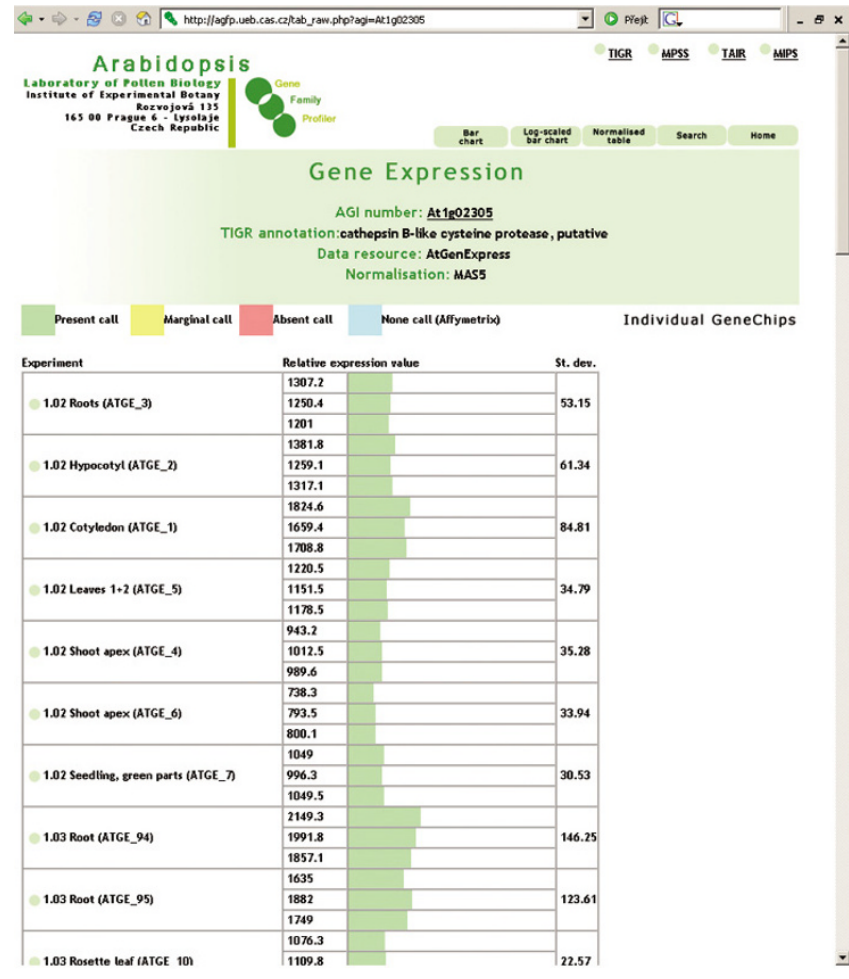

Figure 4

Expression data visualisation. Visualisation of At lg02305 gene expression using Individual GeneChips option.

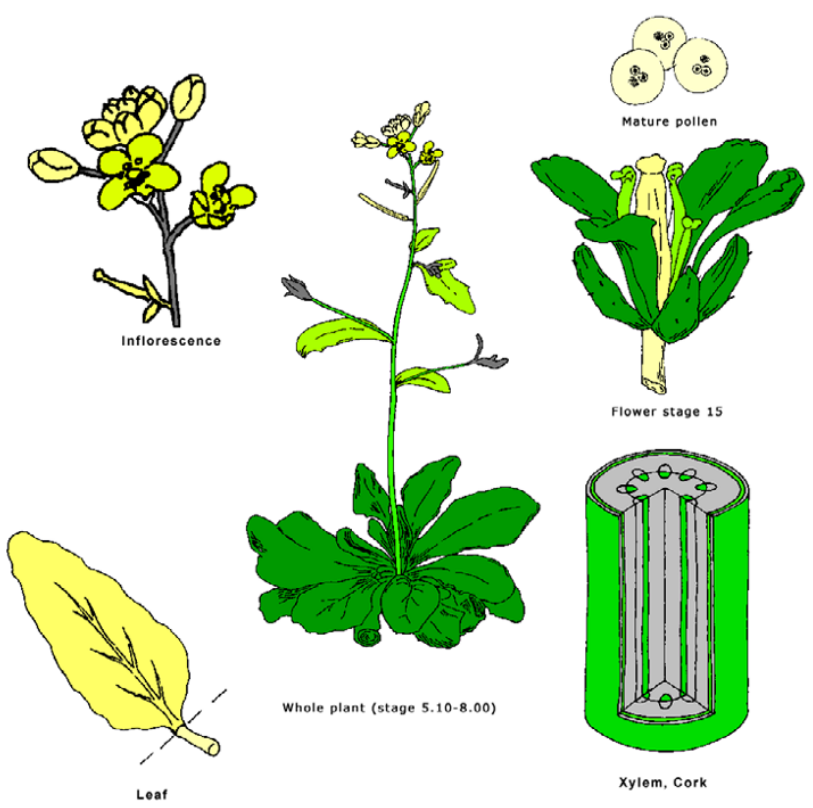

Figure 5

Individual organs visualised by "virtual plant". Detailed expression profile of At I g02305 visualised in selected organs.

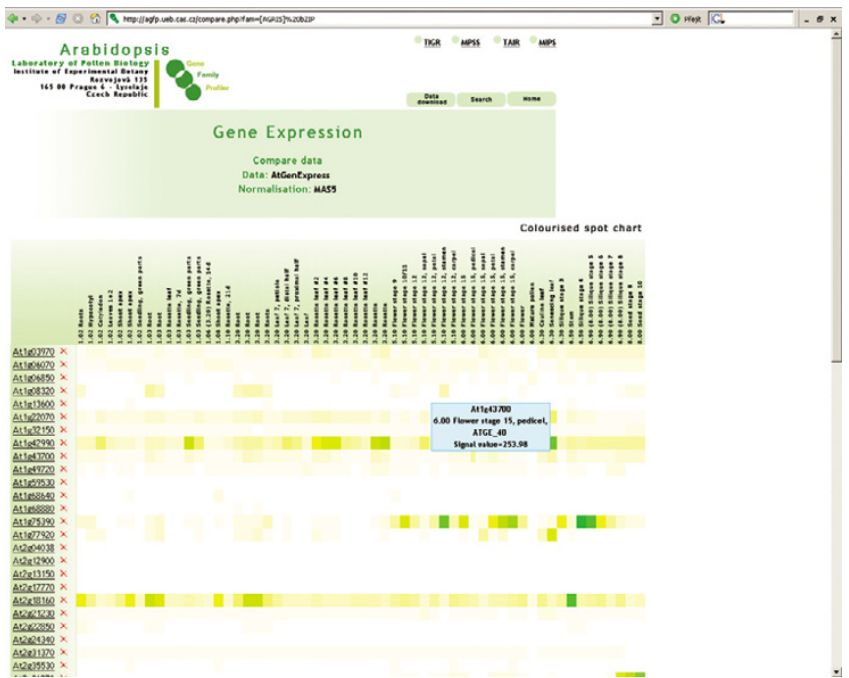

Figure 6

Colourised spot chart visualization. Visualization of expression profiles of bZIP gene family members (AtGenExpress).

profiles of individual genes, gene sets, gene families or gene superfamilies from a broad spectrum of microarray experiments covering various Arabidopsis organs, tissues and developmental stages. For these purposes, an innovative graphic concept of the "virtual plant" was introduced representing a clear and simple visualization of gene expression profiles in a morphological and developmental context. The arabidopsisGFP database is accessible at http://agfp.ueb.cas.cz/.

\section{Authors' contributions}

ND, DT and DH defined the concept of arabidopsisGFP database. ND and $\mathrm{PH}$ programmed all scripts. $\mathrm{DH}$ is responsible for data normalisation. DR worked on gene families and superfamilies definition. DH, DT, ND and $\mathrm{BH}$ specified the data visualization concepts and $\mathrm{BH}$ drew the "virtual plant". All authors read and approved the final manuscript.

\section{Acknowledgements}

Authors gratefully acknowledge the financial support from Grant Agency of The Czech Republic (522/06/0894), MSMT CR (LC06004) and The Royal Society (Joint Project 2004/R3-EU).

\section{References}

I. Analysis of the genome sequence of the flowering plant Arabidopsis thaliana. Nature 2000, 408(68 I4):796-8I5.

2. Project 2010. To determine the functions of all genes in Arabidopsis thaliana by the year 2010 [http://www.nsf.gov/pubs/ 2006/nsf066I2/nsf066/2.htm]

3. Donson J, Fang Y, Espiritu-Santo G, Xing W, Salazar A, Miyamoto S, Armendarez V, Volkmuth W: Comprehensive gene expression analysis by transcript profiling. Plant Mol Biol 2002, 48(I2):75-97.

4. Money T, Reader S, Qu LJ, Dunford RP, Moore G: AFLP-based mRNA fingerprinting. Nucleic Acids Res 1996, 24(13):2616-2617. 
5. Velculescu VE, Zhang L, Vogelstein B, Kinzler KW: Serial analysis of gene expression. Science 1995, 270(5235):484-487.

6. Brenner S, Johnson M, Bridgham J, Golda G, Lloyd DH, Johnson D, Luo S, McCurdy S, Foy M, Ewan M, Roth R, George D, Eletr S, Albrecht G, Vermaas E, Williams SR, Moon K, Burcham T, Pallas M, DuBridge RB, Kirchner J, Fearon K, Mao J, Corcoran K: Gene expression analysis by massively parallel signature sequencing (MPSS) on microbead arrays. Nat Biotechnol 2000, I 8(6):630-634.

7. Lockhart DJ, Dong H, Byrne MC, Follettie MT, Gallo MV, Chee MS, Mittmann M, Wang C, Kobayashi M, Horton H, Brown EL: Expression monitoring by hybridization to high-density oligonucleotide arrays. Nat Biotechnol 1996, 14(13): 1675-1680.

8. Lipshutz RJ, Fodor SP, Gingeras TR, Lockhart DJ: High density synthetic oligonucleotide arrays. Nat Genet 1999, 21(1 Suppl):20-24.

9. Schena M, Shalon D, Davis RW, Brown PO: Quantitative monitoring of gene expression patterns with a complementary DNA microarray. Science 1995, 270(5235):467-470.

10. van Hal NL, Vorst $O$, van Houwelingen AM, Kok EJ, Peijnenburg $A$ Aharoni A, van Tunen AJ, Keijer J: The application of DNA microarrays in gene expression analysis. J Biotechnol 2000, 78(3):27I-280.

II. Clarke JD, Zhu T: Microarray analysis of the transcriptome as a stepping stone towards understanding biological systems: practical considerations and perspectives. Plant J 2006, 45(4):630-650.

12. Zhu T: Global analysis of gene expression using GeneChip microarrays. Curr Opin Plant Biol 2003, 6(5):418-425.

13. Aharoni $A$, Vorst O: DNA microarrays for functional plant genomics. Plant Mol Biol 2002, 48( I-2):99-1 I8.

14. Hennig L, Menges M, Murray JA, Gruissem W: Arabidopsis transcript profiling on Affymetrix GeneChip arrays. Plant Mol Biol 2003, 53(4):457-465.

15. Brazma A, Hingamp $P$, Quackenbush J, Sherlock G, Spellman $P$ Stoeckert C, Aach J, Ansorge W, Ball CA, Causton HC, Gaasterland T, Glenisson P, Holstege FC, Kim IF, Markowitz V, Matese JC, Parkinson H, Robinson A, Sarkans U, Schulze-Kremer S, Stewart J, Taylor R, Vilo J, Vingron M: Minimum information about a microarray experiment (MIAME)-toward standards for microarray data. Nat Genet 200I, 29(4):365-37I.

16. ArrayExpress [http://www.ebi.ac.uk/arrayexpress/?]

17. Gene Expression Omnibus [http://www.ncbi.nlm.nih.gov/geo/]

18. NASCarrays [http://affymetrix.arabidopsis.info/]

19. Gollub J, Ball CA, Sherlock G: The Stanford Microarray Database: a user's guide. Methods Mol Biol 2006, 338: $191-208$.

20. Ball CA, Awad IA, Demeter J, Gollub J, Hebert JM, Hernandez-Boussard T, Jin H, Matese JC, Nitzberg M, Wymore F, Zachariah ZK, Brown PO, Sherlock G: The Stanford Microarray Database accommodates additional microarray platforms and data formats. Nucleic Acids Res 2005, 33(Database issue):D580-2.

21. Stanford Microarray Database [http://genome-www5.stan ford.edu/]

22. Parkinson H, Sarkans U, Shojatalab M, Abeygunawardena N, Contrino S, Coulson R, Farne A, Lara GG, Holloway E, Kapushesky M, Lilja P, Mukherjee G, Oezcimen A, Rayner T, Rocca-Serra P, Sharma A, Sansone S, Brazma A: ArrayExpress--a public repository for microarray gene expression data at the EBI. Nucleic Acids Res 2005 , 33 (Database Issue):D553-5.

23. Barrett T, Suzek TO, Troup DB, Wilhite SE, Ngau WC, Ledoux $P$, Rudnev D, Lash AE, Fujibuchi W, Edgar R: NCBI GEO: mining millions of expression profiles--database and tools. Nucleic Acids Res 2005, 33 (Database Issue):D562-6.

24. Edgar R, Domrachev M, Lash AE: Gene Expression Omnibus: NCBI gene expression and hybridization array data repository. Nucleic Acids Res 2002, 30(I):207-210

25. Gollub J, Ball CA, Binkley G, Demeter J, Finkelstein DB, Hebert JM, Hernandez-Boussard T, Jin H, Kaloper M, Matese JC, Schroeder M, Brown PO, Botstein D, Sherlock G: The Stanford Microarray Database: data access and quality assessment tools. Nucleic Acids Res 2003, 31 ( I):94-96

26. Craigon DJ, James N, Okyere J, Higgins J, Jotham J, May S: NASCArrays: a repository for microarray data generated by NASC's transcriptomics service. Nucleic Acids Res 2004, 32(Database issue): $\mathrm{D} 575-7$.
27. Hughes TR, Marton MJ, Jones AR, Roberts CJ, Stoughton R, Armour CD, Bennett HA, Coffey E, Dai H, He YD, Kidd MJ, King AM, Meyer MR, Slade D, Lum PY, Stepaniants SB, Shoemaker DD, Gachotte D, Chakraburtty K, Simon J, Bard M, Friend SH: Functional discovery via a compendium of expression profiles. Cell 2000, 102(I): 109-126.

28. Mandaokar A, Thines B, Shin B, Markus Lange B, Choi G, Koo YJ, Yoo $Y$ J, Choi YD, Browse J: Transcriptional regulators of stamen development in Arabidopsis identified by transcriptional profiling. Plant J 2006, 46(6):984- 1008

29. Genevestigator [https://www.genevestigator.ethz.ch/at/]

30. Zimmermann P, Hirsch-Hoffmann M, Hennig L, Gruissem W: GENEVESTIGATOR. Arabidopsis Microarray Database and Analysis Toolbox. Plant Physiol 2004, I36(I):262I-2632.

31. Toufighi K, Brady SM, Austin R, Ly E, Provart N]: The Botany Array Resource: e-Northerns, Expression Angling, and promoter analyses. Plant J 2005, 43(I): 153-163.

32. Kapushesky M, Kemmeren P, Culhane AC, Durinck S, Ihmels J, Korner C, Kull M, Torrente A, Sarkans U, Vilo J, Brazma A: Expression Profiler: next generation--an online platform for analysis of microarray data. Nucleic Acids Res 2004, 32(Web Server issue):W465-70.

33. Expression Profiler [http://ep.ebi.ac.uk/EP/]

34. Bulow L, Schindler M, Hehl R: PathoPlant: a platform for microarray expression data to analyze co-regulated genes involved in plant defense responses. Nucleic Acids Res 2007, 35(Database issue):D84I-5.

35. PathoPlant [http://www.pathoplant.de]

36. Manfield IW, Jen CH, Pinney JW, Michalopoulos I, Bradford JR, Gilmartin PM, Westhead DR: Arabidopsis Co-expression Tool (ACT): web server tools for microarray-based gene expression analysis. Nucleic Acids Res 2006, 34(Web Server issue):W504-9.

37. Jen $\mathrm{CH}$, Manfield IW, Michalopoulos I, Pinney JW, Willats WG, Gilmartin PM, Westhead DR: The Arabidopsis co-expression tool (ACT): a WWW-based tool and database for microarraybased gene expression analysis. Plant J 2006, 46(2):336-348.

38. Arabidopsis Co-Expression Tool [http://www.arabidop sis.leeds.ac.uk/act/]

39. NASC AffyWatch transcriptomics service [http://affyme trix.arabidopsis.info/AffyWatch.html]

40. JpGraph [http://www.aditus.nu/ipgraph/]

4l. dChip Software [http://biosun I.harvard.edu/complab/dchip/]

42. $\mathrm{Li} \mathrm{C}$, Wong WH: Model-based analysis of oligonucleotide arrays: expression index computation and outlier detection. Proc Natl Acad Sci U S A 200 I, 98(I):3I-36.

43. $\mathrm{Li} \mathrm{C}$, Hung Wong W: Model-based analysis of oligonucleotide arrays: model validation, design issues and standard error application. Genome Biol 200I, 2(8):RESEARCH0032.

44. Boyes DC, Zayed AM, Ascenzi R, McCaskill AJ, Hoffman NE, Davis KR, Gorlach J: Growth stage-based phenotypic analysis of Arabidopsis: a model for high throughput functional genomics in plants. Plant Cell 200I, I3(7):1499-15I0.

45. Wortman JR, Haas BJ, Hannick LI, Smith RK Jr., Maiti R, Ronning CM, Chan AP, Yu C, Ayele M, Whitelaw CA, White OR, Town CD: Annotation of the Arabidopsis genome. Plant Physiol 2003, | 32(2):46|-468.

46. TAIR Genome Annotation [http://www.arabidopsis.org/portals/ genAnnotation/gene structural annotation/annotation data.jsp]

47. TIGR [http://www.tigr.org/]

48. Childs KL, Hamilton JP, Zhu W, Ly E, Cheung F, Wu H, Rabinowicz PD, Town CD, Buell CR, Chan AP: The TIGR Plant Transcript Assemblies database. Nucleic Acids Res 2007, 35(Database issue):D846-5I.

49. MPSS [http://mpss.udel.edu/at/]

50. Rhee SY, Beavis W, Berardini TZ, Chen G, Dixon D, Doyle A, GarciaHernandez M, Huala E, Lander G, Montoya M, Miller N, Mueller LA, Mundodi S, Reiser L, Tacklind J, Weems DC, Wu Y, Xu I, Yoo D, Yoon J, Zhang P: The Arabidopsis Information Resource (TAIR): a model organism database providing a centralized, curated gateway to Arabidopsis biology, research materials and community. Nucleic Acids Res 2003, 3 I ( I ):224-228.

51. TAIR [http://www.arabidopsis.org/]

52. Schoof H, Ernst R, Nazarov V, Pfeifer L, Mewes HW, Mayer KF: MIPS Arabidopsis thaliana Database (MAtDB): an integrated bio- 
logical knowledge resource for plant genomics. Nucleic Acids Res 2004, 32(Database issue):D373-6.

53. MIPS [http://mips.gsf.de/proj/thal/db/]

54. Arabidopsis Gene Family Information [http://www.arabidop sis.org/browse/genefamily/index.jsp]

55. AGRIS [http://arabidopsis.med.ohio-state.edu/]

56. Palaniswamy SK, James S, Sun H, Lamb RS, Davuluri RV, Grotewold E: AGRIS and AtRegNet. a platform to link cis-regulatory elements and transcription factors into regulatory networks. Plant Physiol 2006, I40(3):8I8-829.

57. Liu WM, Mei R, Di X, Ryder TB, Hubbell E, Dee S, Webster TA, Harrington $\mathrm{CA}, \mathrm{Ho} \mathrm{MH}$, Baid J, Smeekens SP: Analysis of high density expression microarrays with signed-rank call algorithms. Bioinformatics 2002, 18(12): 1593-1599.

58. Twell D Oh S.-A., Honys, D.: Pollen development, a genetic and transcriptomic view. In Plant Cell Monographs vol 3, The Pollen Tube Edited by: Malhó R. Springer-Verlag Berlin, Heidelberg:pp 15-45.

59. Schmid M, Davison TS, Henz SR, Pape UJ, Demar M, Vingron M, Scholkopf B, Weigel D, Lohmann JU: A gene expression map of Arabidopsis thaliana development. Nat Genet 2005, 37(5):50I-506.

Publish with Bio Med Central and every scientist can read your work free of charge

"BioMed Central will be the most significant development for disseminating the results of biomedical research in our lifetime. "

Sir Paul Nurse, Cancer Research UK

Your research papers will be:

- available free of charge to the entire biomedical community

- peer reviewed and published immediately upon acceptance

- cited in PubMed and archived on PubMed Central

- yours - you keep the copyright

Submit your manuscript here:

http://www.biomedcentral.com/info/publishing_adv.asp 